\title{
Cost of healthcare for patients with migraine in five European countries: results from the International Burden of Migraine Study (IBMS)
}

\author{
L. M. Bloudek - M. Stokes - D. C. Buse $\cdot$ T. K. Wilcox $\cdot$ R. B. Lipton $\cdot$ \\ P. J. Goadsby • S. F. Varon - A. M. Blumenfeld · Z. Katsarava • \\ J. Pascual $\cdot$ M. Lanteri-Minet $\cdot$ P. Cortelli $\cdot$ P. Martelletti
}

Received: 11 April 2012/Accepted: 7 May 2012/Published online: 29 May 2012

(C) The Author(s) 2012. This article is published with open access at Springerlink.com

\begin{abstract}
Migraine is a disabling neurological disease that affects $14.7 \%$ of Europeans. Studies evaluating the economic impact of migraine are complex to conduct adequately and with time become outdated as healthcare systems evolve. This study sought to quantify and compare direct medical costs of chronic migraine (CM) and episodic migraine (EM) in five European countries. Cross-sectional data collected via a web-based survey were screened for migraine and classified as CM ( $\geq 15$ headache days/month) or EM $(<15$ headache days/month), and included sociodemographics, resource use data and medication use. Unit cost data, gathered using publicly available sources, were analyzed for each type of service, stratified by migraine
\end{abstract}

L. M. Bloudek $(\varangle)$. S. F. Varon

Allergan Inc., 2525 Dupont Drive, Irvine, CA 92612, USA

e-mail: Bloudek_Lisa@Allergan.com

M. Stokes - T. K. Wilcox

United BioSource Corporation, Bethesda, MD, USA

D. C. Buse - R. B. Lipton

Montefiore Headache Center and the Department of Neurology,

Albert Einstein College of Medicine, Bronx, NY, USA

P. J. Goadsby

Headache Group, Department of Neurology,

University of California, San Francisco, San Francisco,

CA, USA

A. M. Blumenfeld

The Neurology Center, Encinitas, CA, USA

Z. Katsarava

Department of Neurology, University of Essen, Essen, Germany

J. Pascual

Area of Clinical Neuroscience, Service of Neurology,

University Hospital "Central de Asturias", Oviedo, Spain status. Univariate and multivariate log-normal regression models were used to examine the relationship between various factors and their impact on total healthcare costs. This economic analysis included data from respondents with migraine in the UK, France, Germany, Italy, and Spain. CM participants had higher level of disability and more prevalent psychiatric disorders compared to EM. CM participants had more provider visits, emergency department/hospital visits, and diagnostic tests; the medical costs were three times higher for CM than EM. Per patient annual costs were highest in the UK and Spain and lower in France and Germany. CM was associated with higher medical resource use and total costs compared to EM in all

\section{Lanteri-Minet}

Département d'Evaluation et traitement de la Douleur Médecine palliative, Pôle Neurosciences Cliniques du CHU de Nice, Hôpital Cimiez, Nice Cedex, France

\section{P. Cortelli}

IRCCS Institute of Neurological Sciences, Bologna, Italy

P. Cortelli

Department of Neurological Sciences,

Alma Mater Studiorum, University of Bologna, Bologna, Italy

P. Martelletti

Department of Clinical and Molecular Medicine, Sapienza

University of Rome, Regional Referral Headache Centre,

Sant'Andrea Hospital, Rome, Italy 
study countries, suggesting that treatments that reduce headache frequency could decrease the clinical and economic burden of migraine in Europe. Comparing patterns of care and outcomes among countries may facilitate the development of more cost-effective care, and bring greater recognition to patients affected by migraine.

Keywords Migraine - Chronic migraine - Episodic migraine - Cost - Resource utilization - United Kingdom · Spain $\cdot$ France $\cdot$ Italy $\cdot$ Germany

\section{Introduction}

Migraine is a complex and disabling neurological condition that produces substantial disability in nearly all facets of life of persons with migraine, including employment, household work, and social activities [1]. The World Health Organization (WHO) ranks migraine 19th among all causes of years lived with disability [2]. According to a recent review, $14.7 \%$ of adults $(8 \%$ of men and $17 \%$ of women) in Europe have migraine [3]. The cost of migraine in Europe is estimated at $€ 27$ billion annually due to the high prevalence of the disorder and substantial associated social, direct, and indirect costs $[4,5]$.

Migraine may be divided into two types based on headache frequency: episodic migraine (EM, $<15$ headache days per month) or chronic migraine ( $\mathrm{CM}, \geq 15$ headache days per month). The International Classification of Headache Disorders Revised Criteria (ICHD-IIR) Appendix A1.5.1 defines chronic migraine as $\geq 15$ headache days per month for at least 3 months, with $\geq 8$ days per month fulfilling criteria for migraine without aura, in the absence of medication overuse and that cannot be attributed to another causative disorder [6]. The frequency of headache attacks in people with migraine may either increase or decrease over time. CM as a condition that often begins with episodic attacks which then increase in frequency over months or years to finally become a headache on more days than not or even a daily or almost daily mixture of tensiontype headache and migraine [7]. Each year, approximately $2.5 \%$ of persons with EM develop new-onset CM [8].

A recent prevalence estimate of CM in the US population in the American Migraine Prevalence and Prevention (AMPP) study among 162,756 individuals aged $\geq 12$ years was found to be approximately $1 \%(0.91 \%$ overall, $1.29 \%$ of females and $0.48 \%$ of males) [9]. This study used criteria for EM and CM similar to those in the current study. Estimates of the worldwide prevalence of $\mathrm{CM}$ range from approximately 1.4-2.2\%, however, it the most common disorder seen in headache specialty practices and is often characterized as a condition that is both serious and difficult to treat $[10,11]$.
Both clinic and population-based studies have demonstrated that in comparison with those with EM, those with $\mathrm{CM}$ have greater headache-related disability, headache impact, worse socioeconomic status, worse health-related quality of life, higher rates of comorbid medical and psychiatric conditions, increased healthcare resource utilization, and higher direct and indirect costs [12-18].

Studies in Europe of those with chronic daily headache (experiencing $\leq 15$ headache days per month), many of which may also meet the criteria as living with chronic migraine, have found significantly lower quality of life as measured by the SF-36, most notably the general health, vitality, and mental health concepts $[19,20]$.

Migraine prophylaxis is a major component of the management of migraine with the aim of reducing the frequency, duration, and severity of attacks as well as increasing the effect of acute treatment [21]. A number of different prophylactic therapies are either currently in use or being evaluated for the prevention of migraine. Economic burden of illness studies quantifying the differences in healthcare costs between CM and EM are particularly important in order to estimate the potential economic impact prophylactic agents may have either through reducing the transition from $\mathrm{EM}$ to $\mathrm{CM}$ or by facilitating $\mathrm{CM}$ remission.

In the United States and Canada, CM has been found to account for significantly higher healthcare costs compared to EM due to physician visits, emergency department visits, hospitalizations, and medications [18]. In addition to higher direct healthcare costs, the AMPP study has demonstrated a substantial indirect cost attributed to CM due to adverse effects on employment and productivity [17]. Although several studies have characterized the economic burden of migraine in general in Europe, to the best of our knowledge no study conducted to date has examined the impact of CM on healthcare costs [22-24]. Additionally, many of these studies were conducted using data collected prior to 1995 and results are likely not generalizable to today's patients seeking migraine treatment [25]. The purpose of this work was to address these gaps using medical resource use data collected as part of the International Burden of Migraine Study (IBMS).

\section{Methods}

Data source and patient population

Data for the current economic analysis comes from a global, cross-sectional, web-based survey administered from February to April 2009. The core survey developed in English for the United States was subsequently adapted 
using country-specific validated translations of clinical and quality of life measures. A full description of the survey methods as well as the inclusion/exclusion criteria have been described elsewhere [26]. Individuals who had previously reported having experienced headaches or migraine were identified from panels maintained by Synovate Healthcare (Chicago, IL, USA). Study inclusion criteria included being at least 18 years of age, having an active e-mail address, the ability to read and understand the official language(s) in the participant's country of residence, and a self-report of having headaches not associated with a cold, flu, head injury, or hangover in the past 3 months. Those agreeing to participate in the study provided consent by "opting in" using a web link provided in an e-mail invitation. A central ethics review board approved the study design and materials (Institutional Review Board Services, Ontario, Canada). Synovate provided participants with points, redeemable for modest cash rewards for their participation in the study.

Participants were selected via screening questions assessing the International Classification of Headache Disorders, 2nd Edition (ICHD-2) diagnostic criteria for migraine and were classified into chronic $(\geq 15$ headache days per month) or episodic $(<15$ headache days per month) migraine subgroups using headache frequency data. The ICHD-II criteria for CM were modified based on available data. Respondents were not assessed for meeting the ICHD-II criteria of $\geq 8$ migraine days per month, thus meet criteria for chronic daily headache with a diagnosis of migraine disorder. Participants in the United Kingdom, Italy, Spain, France, and Germany were selected for inclusion into the study $(n=5,657)$.

\section{Sociodemographic and clinical study measures}

Data on sociodemographic characteristics including age, gender, race, and education status were collected as part of the cross-sectional survey. Information related to comorbid conditions was collected via participants' selfreport of a physician diagnosis. Specific conditions were identified through response option endorsement to the question "Have you been told by a doctor or any other health professional that you have any of the following health problems?" Participants were categorized based on the conditions into five subgroups (psychiatric, pain, vascular risk factors, vascular disease events, and other). The survey also included a ten-point visual analog scale for the measurement of headache intensity. Intensity was categorized as follows: mild $(\leq 4)$, moderate $(5-7)$, severe (7 and 8), and very severe ( 9 and 10). Additionally, the survey measured disability using the Migraine Disability Assessment (MIDAS) questionnaire [27].
Headache-related disability

The MIDAS questionnaire assesses headache-related disability and is the most frequently used disability instrument in migraine research and clinical practice $[1,28,29]$. It is a self-administered questionnaire consisting of five items that assess days of missed activity or substantially reduced activity due to headache in three domains-schoolwork/ paid employment, household work or chores, and non-work (family, social, and leisure) activities. Responses to these items are summed for a total score, which can be categorized into one of four grades of headache-related disability: Grade I, little or no disability (score of 0-5); Grade II, mild disability (score of 6-10); Grade III, moderate disability (score of 11-20); and Grade IV, severe disability (score of $\geq 21$ ).

MIDAS was originally developed and validated for use with a general headache sample. The standard MIDAS grading system groups patients with scores of 21 and above into a single category of "severe disability." While this division works well for episodic migraine, a disproportionately large number of persons with chronic migraine fall into Grade IV. Accordingly, for this study, we subdivided the most severe category of Grade IV [30].

\section{Healthcare resource use data}

Participants were asked to record the frequency of visits to various health care professionals occurring over the preceding 3 months for headache treatment or diagnostic evaluation. Participants could choose from various types of health care provider visits including primary care physician, neurologist, headache specialist, nurse practitioner, physician assistant, obstetrician/gynecologist, pain specialist, and psychologist, psychiatrist, or social worker. Choices for various categories of diagnostic testing included magnetic resonance imaging (MRI), computed tomography (CT), electroencephalogram (EEG), electrocardiogram (ECG), and blood tests. Data on the frequency with which specific headache-related procedures or devices including botulinum toxin type A injections, transcutaneous electronic nerve stimulator (TENS), and acupuncture were performed or prescribed during the preceding 3 months were collected. Participants were also asked to record the total number of nights spent in a hospital or clinic and the total number of visits to the emergency department (ED) for headacherelated treatment in the preceding 3 months. Finally, study participants were provided with a list of medications commonly used as migraine acute and preventive pharmacotherapy unique to each participant's country. Participants were then asked to identify any medications used in the preceding 4 weeks and to record the number of days of use 
Table 1 Unit cost estimates used for the United Kingdom, France, Italy, Spain, and Germany (in €2010)

\begin{tabular}{|c|c|c|c|c|c|}
\hline \multirow[t]{2}{*}{ Cost measure } & \multicolumn{5}{|l|}{ Unit costs } \\
\hline & UK & France & Italy & Spain & Germany \\
\hline Primary care physician visit & $€ 55[34]$ & $€ 23[31]$ & $€ 24[35]$ & $€ 32[36]$ & $€ 32[32]$ \\
\hline Neurologist/headache specialist visit & $€ 165[33]$ & $€ 35[31]$ & $€ 24[35]$ & $€ 54[36]$ & $€ 32[32]$ \\
\hline Nurse practitioner/physician assistant visit & $€ 13[34]$ & $€ 10[31]$ & - & $€ 13[36]$ & - \\
\hline $\mathrm{OB} / \mathrm{GYN}$ visit & $€ 114[33]$ & $€ 23[31]$ & $€ 24[35]$ & $€ 45[36]$ & $€ 28[32]$ \\
\hline Pain specialist visit & $€ 126[33]$ & $€ 23[31]$ & $€ 24[35]$ & $€ 54[36]$ & $€ 24[32]$ \\
\hline Psychologist visit & $€ 54[34]$ & $€ 35^{\mathrm{a}}$ & $€ 20[35]$ & $€ 32[36]$ & $€ 19^{\mathrm{a}}$ \\
\hline Psychiatrist visit & $€ 250[33]$ & $€ 35[31]$ & $€ 20[35]$ & $€ 45[36]$ & $€ 19[32]$ \\
\hline Social worker visit & $€ 47[34]$ & $€ 35^{\mathrm{a}}$ & - & $€ 45^{\mathrm{a}}$ & $€ 19^{\mathrm{a}}$ \\
\hline ER or urgent care visit & $€ 106[33]$ & $€ 25[46]$ & $€ 48^{\mathrm{b}}$ & $€ 125[46]$ & - \\
\hline Inpatient hospital stay daily cost & $€ 424[33]$ & $€ 402[31]$ & $€ 270[43]$ & $€ 485[45]$ & $€ 402[44]$ \\
\hline Magnetic resonance imaging (MRI) & $€ 270[33]$ & $€ 69[31]$ & $€ 236[35]$ & $€ 166[37]$ & $€ 138[32]$ \\
\hline Computed tomography (CT) & $€ 132$ [33] & $€ 25[31]$ & $€ 99[35]$ & $€ 199[38]$ & $€ 72[32]$ \\
\hline Electroencephalogram (EEG) & $€ 135$ [33] & $€ 60[31]$ & $€ 24[35]$ & $€ 167[36]$ & $€ 38[32]$ \\
\hline Electrocardiogram (ECG) & $€ 38[33]$ & $€ 14[31]$ & $€ 12[35]$ & $€ 7$ [39] & $€ 11[32]$ \\
\hline X-ray & $€ 28[33]$ & $€ 24[31]$ & $€ 25[35]$ & $€ 37[36]$ & $€ 13[32]$ \\
\hline Blood tests & Various [33] & Various [31] & Various [35] & Various [38] & Various [32] \\
\hline \multicolumn{6}{|l|}{ Botulinum toxin $\mathrm{A}$ injection } \\
\hline Injection component & $€ 165^{\mathrm{c}}$ & $€ 35^{\mathrm{c}}$ & $€ 24^{\mathrm{c}}$ & $€ 54^{\mathrm{c}}$ & - \\
\hline Botulinum toxin A drug component & $€ 309[51]$ & $€ 450[52]$ & $€ 320[50]$ & $€ 438[39]$ & $€ 625[49]$ \\
\hline Transcutaneous nerve stimulator (TENS) & $€ 53[33]$ & $€ 7[31]$ & $€ 11[35]$ & $€ 24[39]$ & $€ 7[32]$ \\
\hline Acupuncture & $€ 45[40]$ & $€ 47[41]$ & $€ 18[35]$ & $€ 60[42]$ & $€ 32[32]$ \\
\hline Occipital nerve block & $€ 247[33]$ & $€ 84[31]$ & $€ 53$ & $€ 132[39]$ & - \\
\hline Medications & Various [47] & Various [31] & Various [50] & Various [48] & Various [49] \\
\hline
\end{tabular}

$N A$ unit cost was not found for resource use item

${ }^{\text {a }}$ Cost estimate for specialist not found; assumed to be equal to psychiatrist visit

${ }^{\mathrm{b}}$ Assumption, ER care $=2 \times$ cost of GP physician visit

c Assume injection cost is the same as a neurologist visit

for each medication. Data were gathered on acute and prophylactic medications and is listed by class in Table 4 .

Economic study data

Unit costs unique to each country were collected from publicly available sources and applied to health care resource use parameters (Table 1). Cost estimates were collected using a direct medical care perspective and standardized to $€ 2010$. In assigning costs, it was assumed that participants would receive care for a specific resource within the national or regional health system of his/her country of residence. Generally, the costs for each study participant were estimated by multiplying the frequency of use of each reported resource item by the unit cost for that item in the participant's country of residence. If a specific procedure or medication was not reimbursed by the government, an assumption that the patient would either pay out of pocket or receive care in the private system was used, and thus not counted in this analysis. In
Germany, physicians are reimbursed with quarterly lump sums for treating patients during each 3-month period or calendar year quarter regardless of the actual number of times patients are seen. Thus, the calculation of physician visit costs was modified to fit Germany's reimbursement scheme.

Unit costs for most health care provider visits, diagnostic testing, and other procedures were estimated using the fee schedules representing payments made under the national systems for participants residing in France and Germany $[31,32]$. In the UK, average costs published by the Department of Health were used [33, 34]. National price lists for Italy and Spain do not exist. For Italy, unit costs were estimated from the regional fee schedules of Lombardia [35]. Regional fee schedules from Galicia, País Vasco, Junta de Andalucía, and Comunitat Valenciana regions were used for Spain [36-39]. Unit costs for acupuncture were estimated using local websites for the UK, France, and Spain [40-42]. For Germany, the payment for acupuncture to treat chronic pain in the lower spine or 
knees under the public system was used as a proxy for migraine-related treatment. Estimates for nurse practitioner/physician assistant visits were not available for Italy and Germany; it was assumed that the costs for these providers were included in physician remuneration.

Hospital costs were estimated using costs based on the public system reference cost groupers for headache or migraine-related hospital care available in each country [31, 33, 43-45]. Reimbursements paid to hospitals are based on a flat rate per admission which is set according to diagnosis-related groups. In assigning costs, the most conservative or least expensive grouper code was used. ED visits were estimated using public health system data for the UK, France and Spain [33, 36, 46]. ED visit cost estimates could not be identified for Italy and Germany. For Italy, an ED visit was assumed to be twice the cost of a primary care physician visit. As urgent care in Germany is routinely managed by general practitioners, ED visits were assumed to be included in the remuneration of primary care physicians.

Medication cost estimates were obtained from the national formularies of each study country with the exception of Italy [31, 47-49]. For Italy, medication costs were identified from a private site for health care professionals [50]. Since data on medication dose were not collected as part of the internet survey, all medication costs were estimated using daily dose assumptions based on the expert clinical opinion of the study authors who are also physicians. If more than one dose was plausible for a given medication, the midpoint of the plausible range was chosen. For example, for countries in which the price per vial of botulinum toxin type A was available, an average dose of 150 units was assumed in estimating costs since doses in the plausible range of 100-200 units likely would have been prescribed. In the UK and France, botulinum toxin type A unit costs could not be identified using the NHS reference data or the national fee schedules, respectively. Costs were estimated using information obtained from online sources [51, 52]. For all countries, we assumed that the cost associated with the administration of botulinum toxin $\mathrm{A}$ is equal to one neurologist/headache specialist visit.

\section{Data analyses}

Baseline sociodemographic and clinical characteristics including age, gender, race, education, headache-related disability (as measured by MIDAS score), headache intensity, and medical and psychiatric comorbidities were assessed descriptively for each country. Within countries, comparisons between CM and EM groups were made using two-sided Pearson Chi-square for categorical measures and $t$ test statistics for continuous measures. Health care use measures were also summarized using descriptive statistics. Because of the relatively low frequency, some health care resource use items (e.g., hospitalizations), Fisher's exact test was used for group comparisons. Initial data analyses revealed that two participants had very high costs. Upon examination of these patients' resource use profiles, they were excluded from the analysis because of implausibly high values. Statistically significant differences were evaluated at an $\alpha=0.05$.

Healthcare costs were analyzed separately for each resource use category and stratified by migraine status for each of the study countries. A minority of study participants had missing data due to inability to recall medication name or frequency. Health care costs are presented over 3 months as well as annually. Costs were annualized by multiplying the 3 -month average healthcare cost by 4 . Total costs were estimated by summing each individual category.

Analyses of the determinates of costs related to migraine headaches with a particular focus on the impact of headache frequency (CM vs. EM) were conducted using multivariate methods. Gamma regression models with log-link function were fitted separately for each study country to explore the relationship between various factors hypothesized to have an impact on total healthcare costs over 3 months (CM status, MIDAS disability scores, headache intensity, and comorbidities). Associations in these models were measured in terms of expected differences in means of the log of total costs with $95 \%$ confidence intervals. We assessed each determinant separately (in models that included age, gender, and education) and then jointly in a multivariate model. MIDAS disability scores were excluded from multivariate models due to expected collinearity with headache frequency.

\section{Results}

Sociodemographic and clinical characteristics of participants

Sociodemographic and clinical characteristics of the study participants are presented in Table 2 by study country and migraine status. Overall, study groups were comparable with respect to nearly all sociodemographic parameters studied. However, with respect to clinical parameters there were notable differences between groups. For all countries, CM participants reported higher levels of headache-related disability compared to persons with EM $(P<0.001$, all comparisons). The proportion of $\mathrm{CM}$ participants with severe headache-related disability (MIDAS Grade IV-A or IV-B) ranged from $71.4 \%$ in Spain to $90.4 \%$ in Germany, whereas less than one-third of EM participants were classified as Grade IV-A or IV-B (UK $24.0 \%$, France $20.4 \%$, Germany $34.6 \%$, Italy $33.5 \%$, and Spain $23.7 \%$ ). Across 


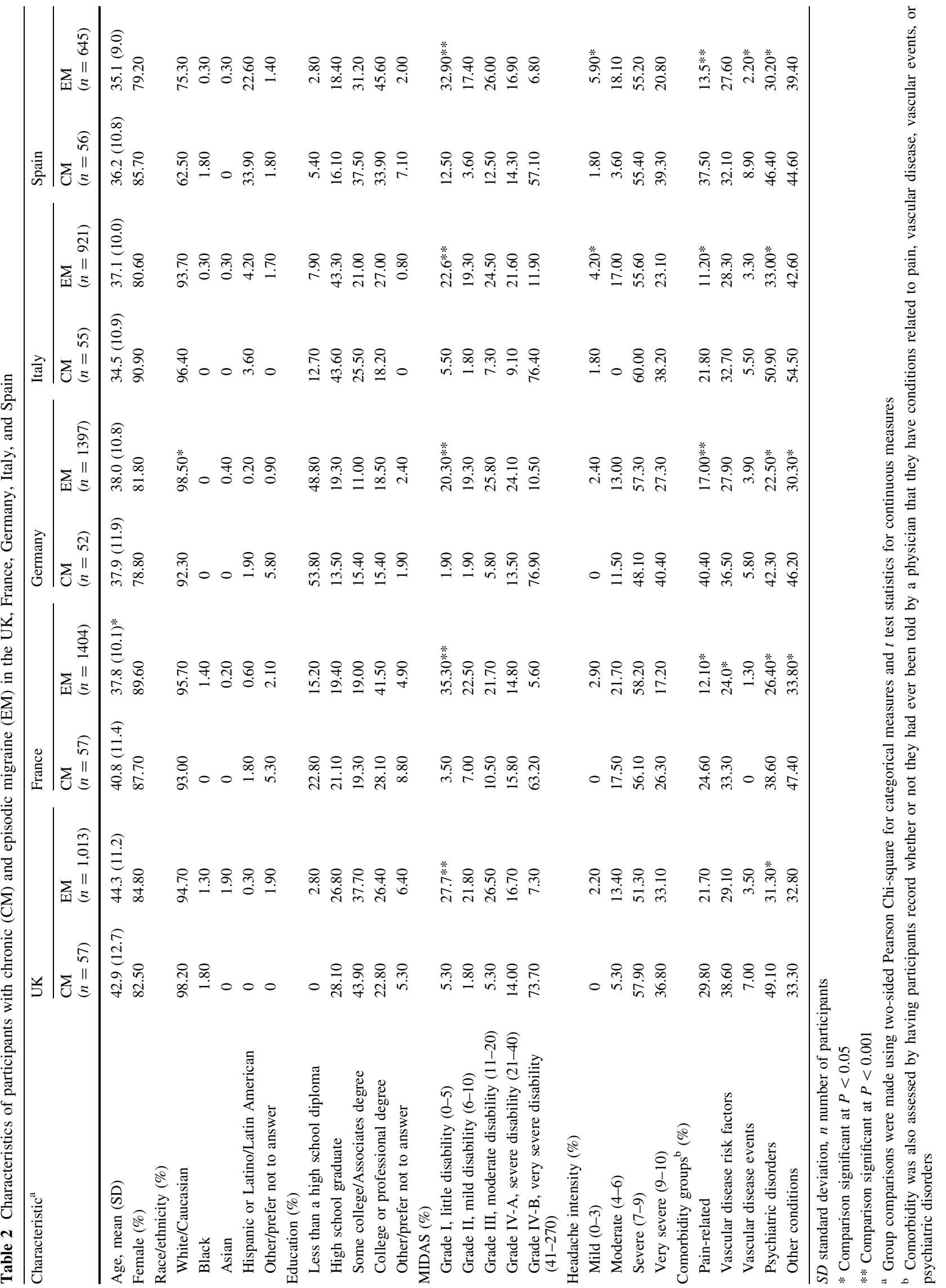




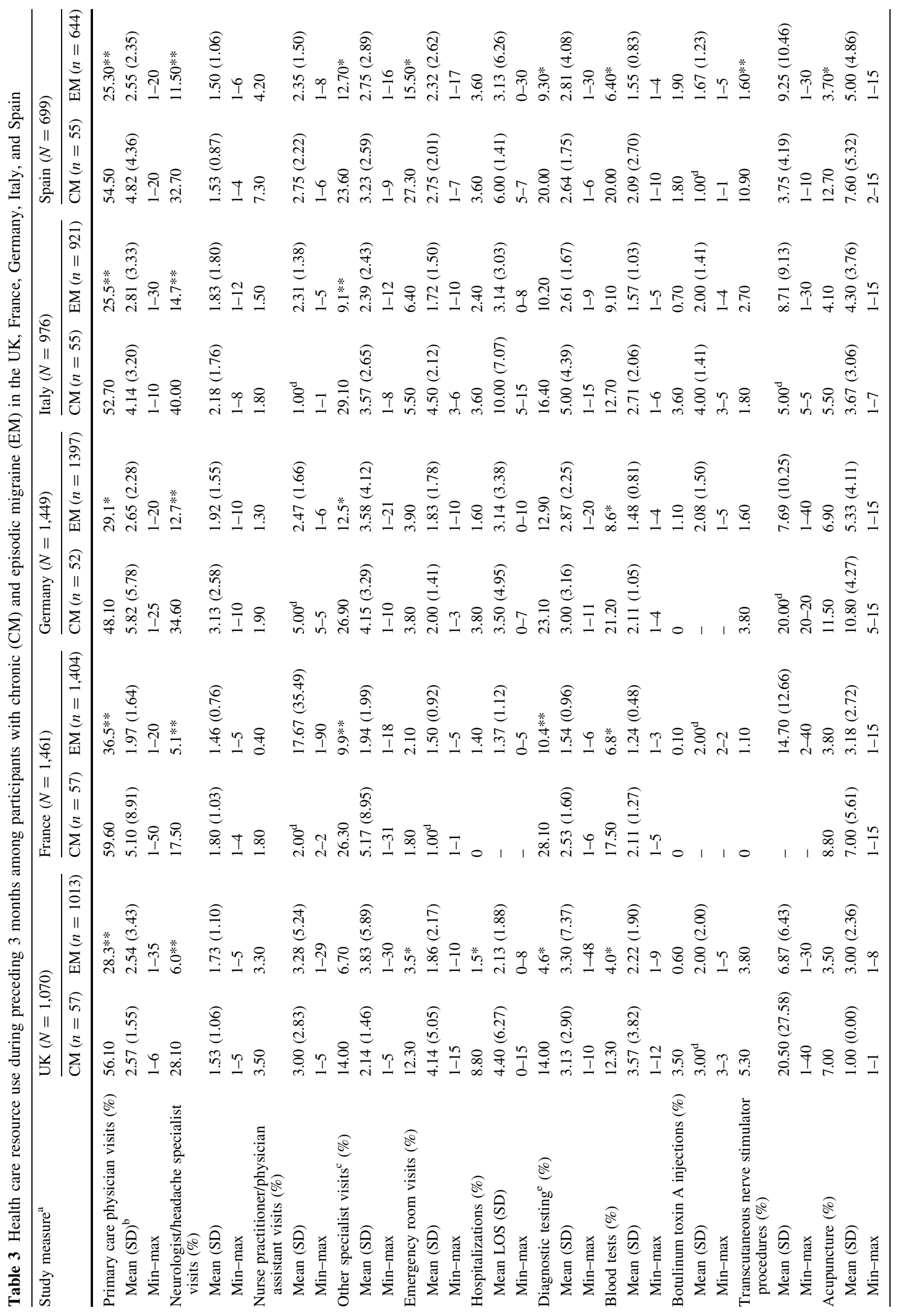




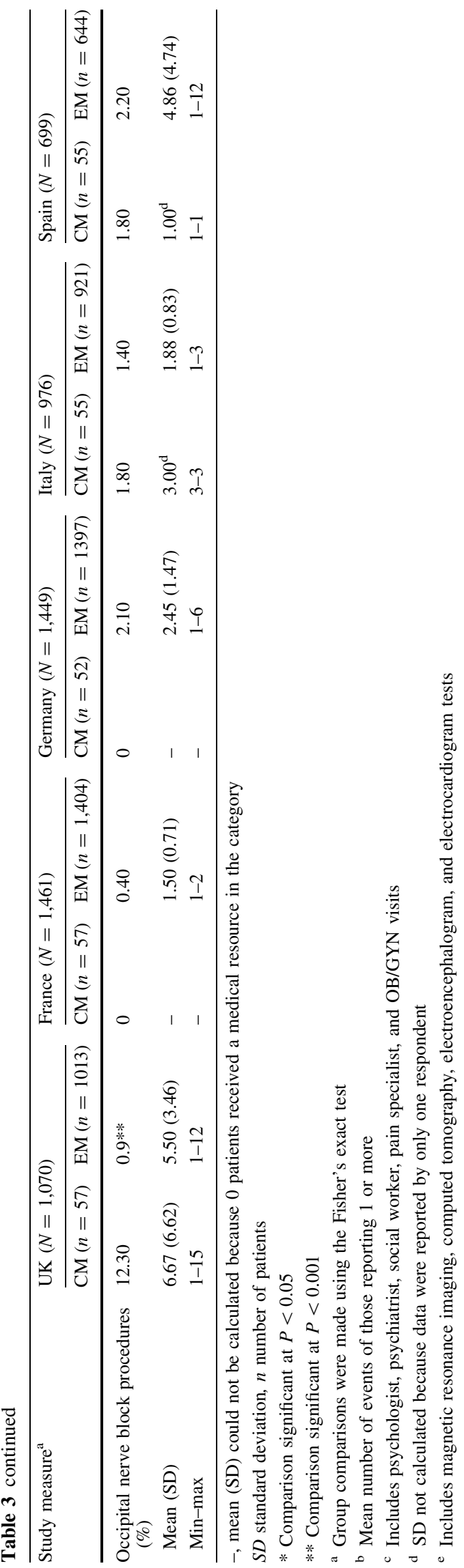

all countries, psychiatric disorders were more prevalent among $\mathrm{CM}$ in comparison to EM $(P<0.05$, all comparisons). Overall, almost one-half $(45.5 \%)$ of CM participants reported having a psychiatric disorder compared to approximately one-third (27.9 \%) of EM participants. In all countries with the exception of the UK, a greater proportion of participants reported having a comorbidity related to pain compared to $\mathrm{EM}(P<0.05$ for France and Italy and $P<0.001$ for Germany and Spain). In France, approximately one-third $(33.3 \%)$ of $\mathrm{CM}$ participants reported having a vascular disease risk factor versus one-quarter $(24.6 \%)$ of EM participants $(P<0.05)$.

Healthcare resource use related to migraine

Table 3 presents data on headache-related medical resources (excluding medications) used by the study participants in the past 3 months and Fig. 1 presents the annualized mean total healthcare costs per patient by migraine group and country. Overall, the most common services utilized by migraine participants were healthcare provider visits, diagnostic testing, and blood tests. The utilization of these services was similar across countries. Over half (54.5\%) of European CM participants reported visiting a primary care physician for headache over the previous 3 months, in contrast to only one-third $(29.8 \%)$ of EM $(P<0.05$, for each comparison within countries). Differences in the extent in which $\mathrm{CM}$ and EM participants utilized neurologist/headache specialist visits were also striking with nearly one-third $(30.7 \%)$ and $9.7 \%$ of CM and EM, respectively, reporting having visited a neurologist or headache specialist $(P<0.001)$. CM participants also utilized diagnostic testing to a greater extent compared with EM in the UK (CM 14.0\%; EM 4.6\%, $P<0.05$ ), France (CM $28.1 \%$; EM $10.4 \%, P<0.001$ ), and Spain (CM $21.4 \%$; EM $9.5 \%, P<0.05$ ). Blood tests were also utilized to a much greater extent among $\mathrm{CM}$ versus EM participants in the UK (12.3 vs. $4.0 \%, P<0.05)$, France (17.5 vs. $6.8 \%, P<0.05)$, Germany ( 21.2 vs. $8.6 \%$, $P<0.05)$, and Spain $(21.4$ vs. $6.4 \%, P<0.001)$.

Overall, the proportion of participants reporting an ED visit was much higher in Spain (16\%) compared to the UK (4\%) France (2\%), Germany (4\%), and Italy (6\%). CM participants were more likely to report having an ED visit compared to EM in the UK (12.3 and $3.5 \%$, respectively, $P<0.05)$ and Spain (28.6 and $15.5 \%$, respectively, $P<0.05)$. The proportion reporting a hospitalization for migraine treatment was also higher in Spain $(3.6 \%)$ compared to the UK (1.9\%), France (1.3\%), Germany (1.7\%), and Italy $(2.5 \%)$. However, only in the UK was the use of hospital services significantly higher for $\mathrm{CM}$ versus EM participants (CM $8.8 \%$; EM $1.5 \%, P<0.05$ ) (Table 3).

Table 4 displays acute and prophylactic medication use data by medication class. The frequency of over the 


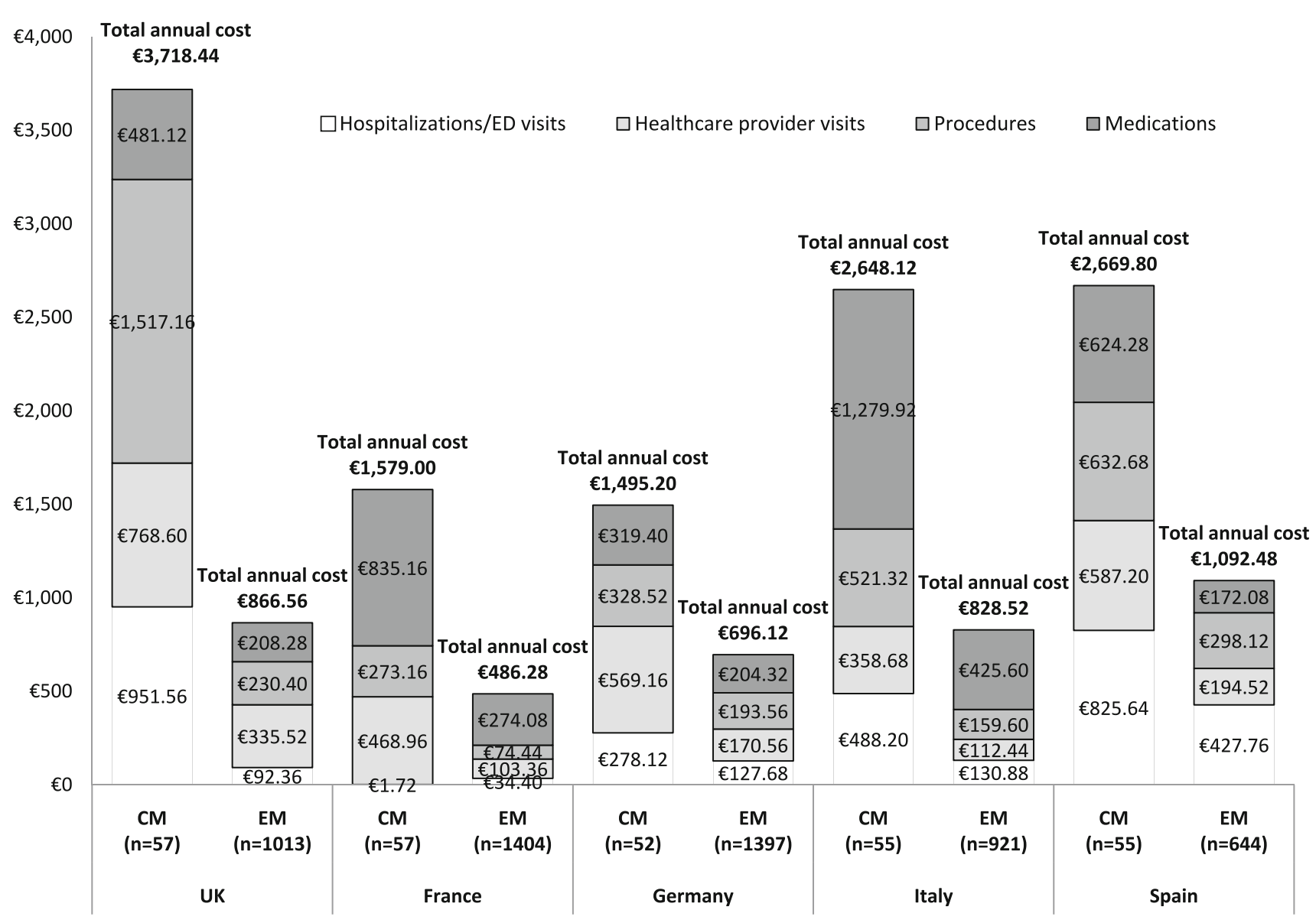

Fig. 1 Mean total annual costs per patient by migraine group

counter or prescription medication use varied across study countries. Medication use was highest in the UK (75.4\%) and France $(72.5 \%)$, followed by Italy (65.1\%), Spain (64.1\%) and Germany (49.0\%). Medication use among CM participants was significantly higher compared to EM in France (CM 87.7 \%; EM 71.9 \%, $P<0.05)$, Italy (CM $83.6 \%$; EM 64.0\%, $P<0.05$ ), and Spain (CM $91.1 \%$; EM $61.9 \%, P<0.05)$ but not in the UK or Germany. CM participants used acute medications to a greater extent compared to EM in Italy (CM 56.4\%; EM $35.5 \%$, $P<0.05)$ and Spain (CM 87.3\%; EM 59.2 \%, $P<0.05)$. Use of prophylactic medications was significantly higher in CM versus EM participants in Spain only (CM $23.6 \%$; EM $7.5 \%, P<0.05)$ (Table 5).

Factors influencing total costs

Results of univariate and multivariate models are presented in Table 6. Results of univariate analysis of headache frequency show that $\mathrm{CM}$ is associated with higher 3-month total healthcare costs compared to EM across all countries $(P<0.05$ for all). Total costs for CM and EM by country are also presented in Fig. 1. Overall, the costs of care for
EM were highest in Spain followed by the UK, Italy, Germany and France. The costs of CM medical care were highest in Spain followed by the UK and Italy and then France and Germany. After adjusting for headache intensity and comorbidities, CM status was associated with higher total healthcare costs compared to EM for all countries except Germany. Differences were highest in the UK, where CM participants had mean total healthcare costs 3.6-fold higher than EM participants (95 \% CI 2.2-6.0) in multivariate analysis, controlling for headache intensity and comorbidities (Table 6). Costs were 2.3-fold higher in France (95\% CI 1.5-3.5), 1.5-fold higher in Germany (95\% CI 0.83-2.7), 2.5-fold higher in Italy (95\% CI 1.5-3.9), and 2.0-fold higher in Spain (95 \% CI: 1.2-3.4). Univariate analysis of MIDAS Grades III (moderate disability), IV-A (severe disability), and IV-B (very severe disability) compared to Grade I (little disability) showed that higher disability was associated with higher healthcare costs across all countries $(P<0.0001)$. Headache intensity is generally only associated with higher healthcare-related cost when comparing very severe to mild intensity. The effect of comorbidities varied substantially by country. Presence of pain-related comorbidities were associated 


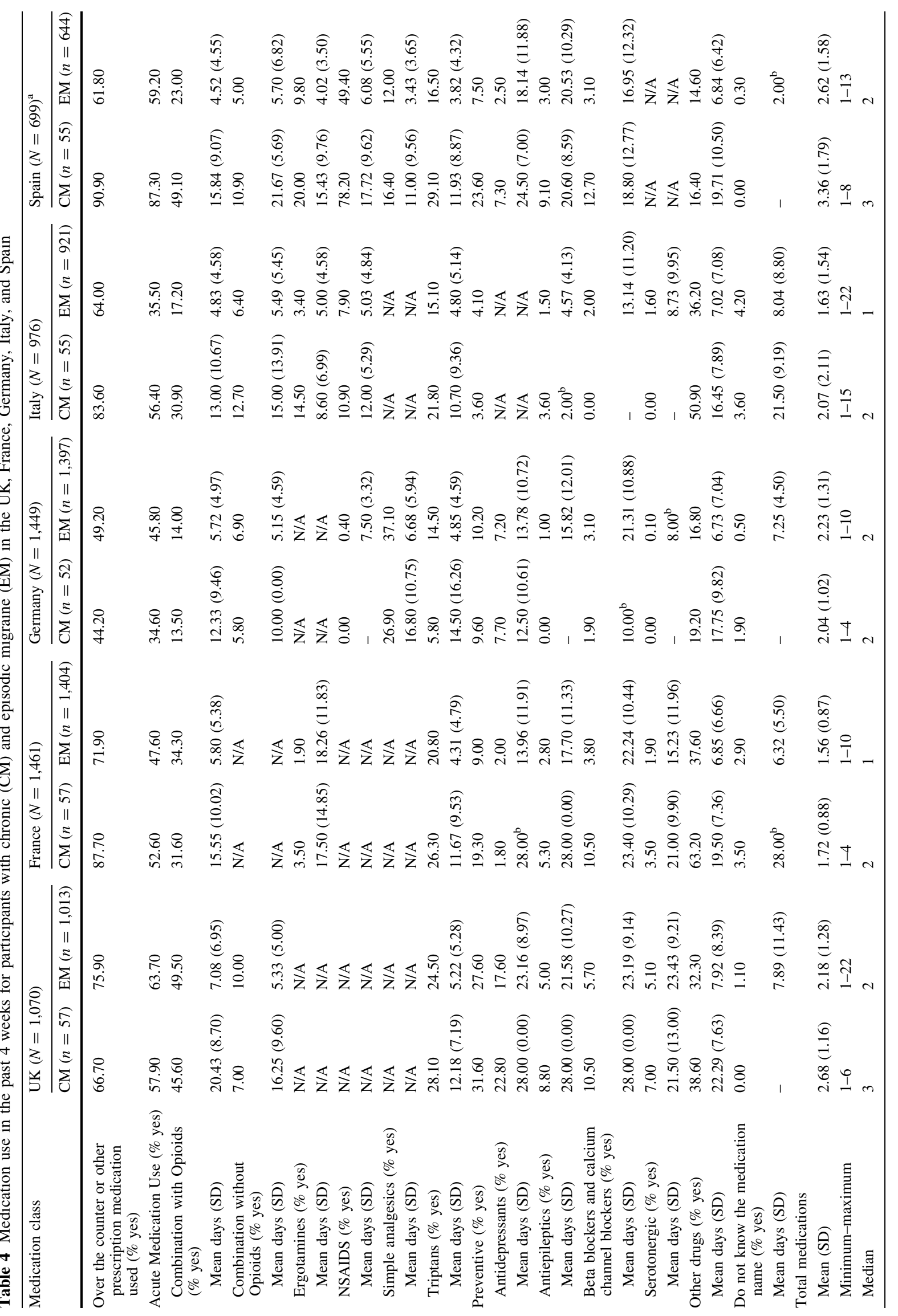




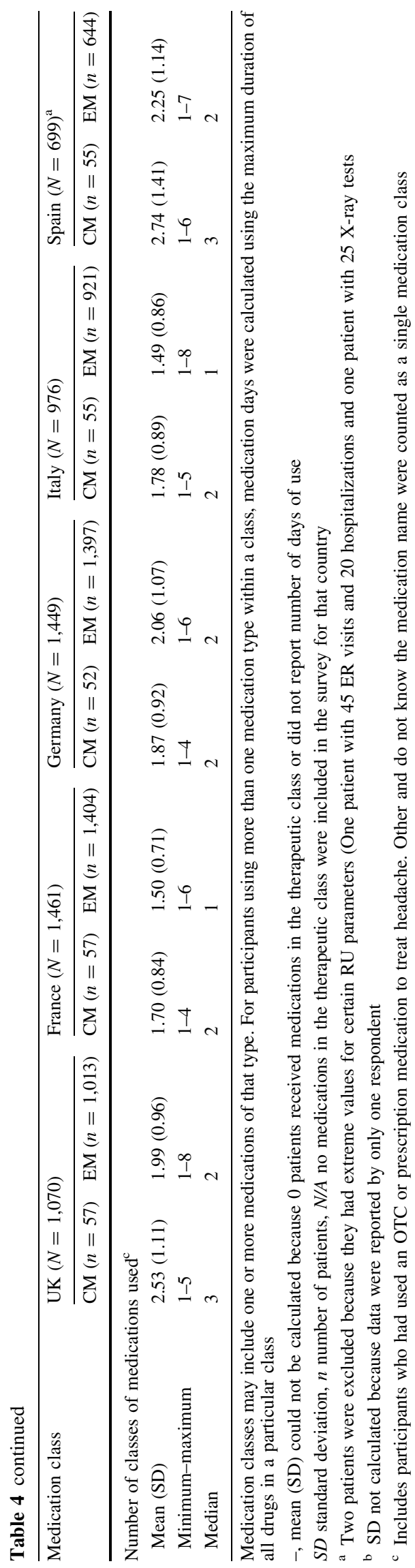

with higher cost across all countries, but these associations were only maintained in multivariate analysis for the UK (1.4-fold increase, $95 \%$ CI 1.1-1.7), France (1.5-fold increase, $95 \%$ CI 1.2-1.8), and Germany (1.8-fold increase, $95 \%$ CI 1.5-2.3). Vascular disease risk factors were associated with higher healthcare costs across all countries except Germany, but associations were only maintained in multivariate analysis for the UK (1.2-fold increase, $95 \%$ CI 1.0-1.4) and Spain (1.3-fold increase, $95 \%$ CI 1.0-1.7). Psychiatric comorbidities were associated with higher costs in all countries in univariate analysis $(P<0.01$ for all comparisons). In multivariate analysis, psychiatric comorbidities were associated with 1.3-fold increase in costs in the UK (95\% CI 1.09-1.5), 1.5-fold increase in Germany (95\% CI 1.2-1.8), and 1.6-fold increase in Italy (95 \% CI 1.4-1.9). Statistical significance of psychiatric comorbidities was not maintained in the multivariate models for France or Spain.

\section{Discussion}

Using a large international survey of persons with migraine in five European countries, we found that for every country studied, CM is associated with additional health care costs attributable to an increased use of medical services and associate cost. Among participants with CM, the average healthcare costs over 3 months varied greatly, ranging from $€ 373.8$ in Germany to $€ 929.6$ in the UK. CM was found to be associated with higher total healthcare-related cost even after controlling for headache intensity and comorbidities in all included countries except in Germany. This lack of statistical significance may be attributed to the relatively small difference in average health care costs between CM and EM in Germany (public health care system, controls costs). The difference in mean total healthcare costs between CM and EM per 3 months in Germany was only $€ 199.8$ compared to $€ 713.0$ in the UK, $€ 273.0$ in France, $€ 454.9$ in Italy, and $€ 394.4$ in Spain. The mean cost of care and the major cost drivers varied widely between countries, potentially reflecting differences in available migraine therapies, delivery of care, cost of services, and structural differences in the healthcare systems of these countries.

Our results suggest that there are differences across the five European countries included in this analysis with respect to migraine management. For example, the percentage of CM participants reporting one or more hospitalizations with overnight stay for migraine was more than twice as high for the UK $(8.80 \%)$ compared to any other country (0\% for France, $3.8 \%$ for Germany, $3.6 \%$ for Italy, and $3.6 \%$ for Spain). While these participants accrue higher healthcare costs, the greater proportion of $\mathrm{CM}$ 


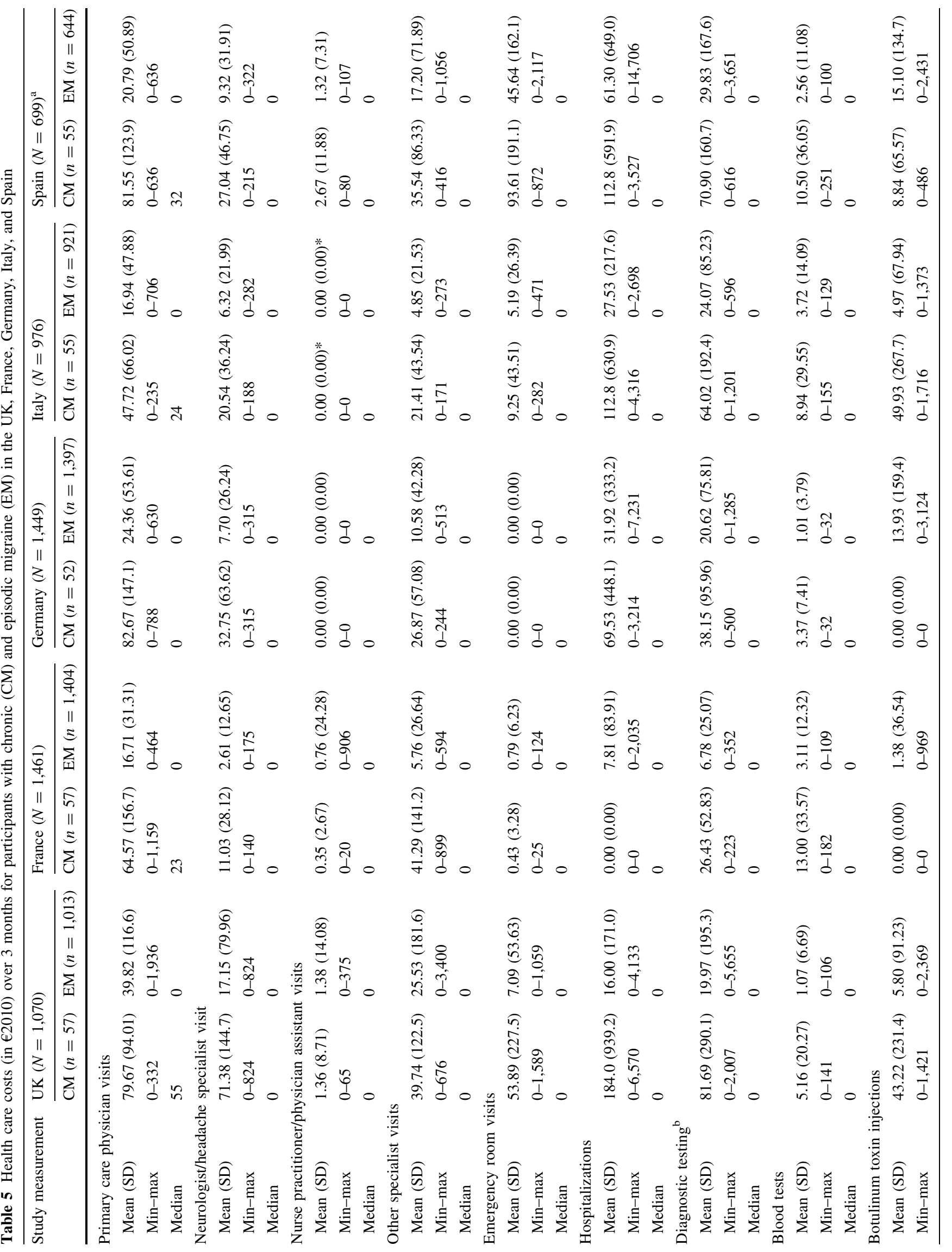




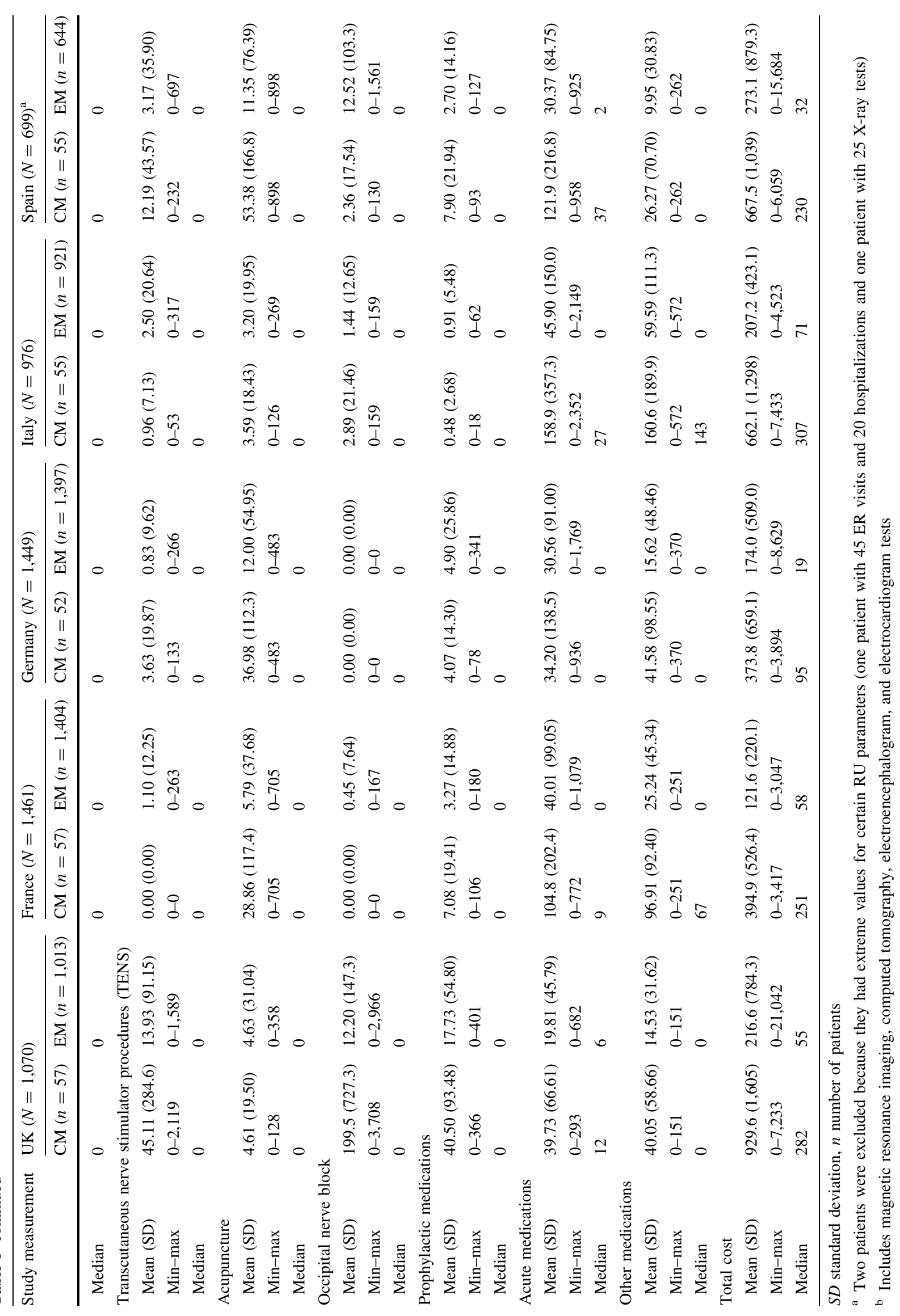




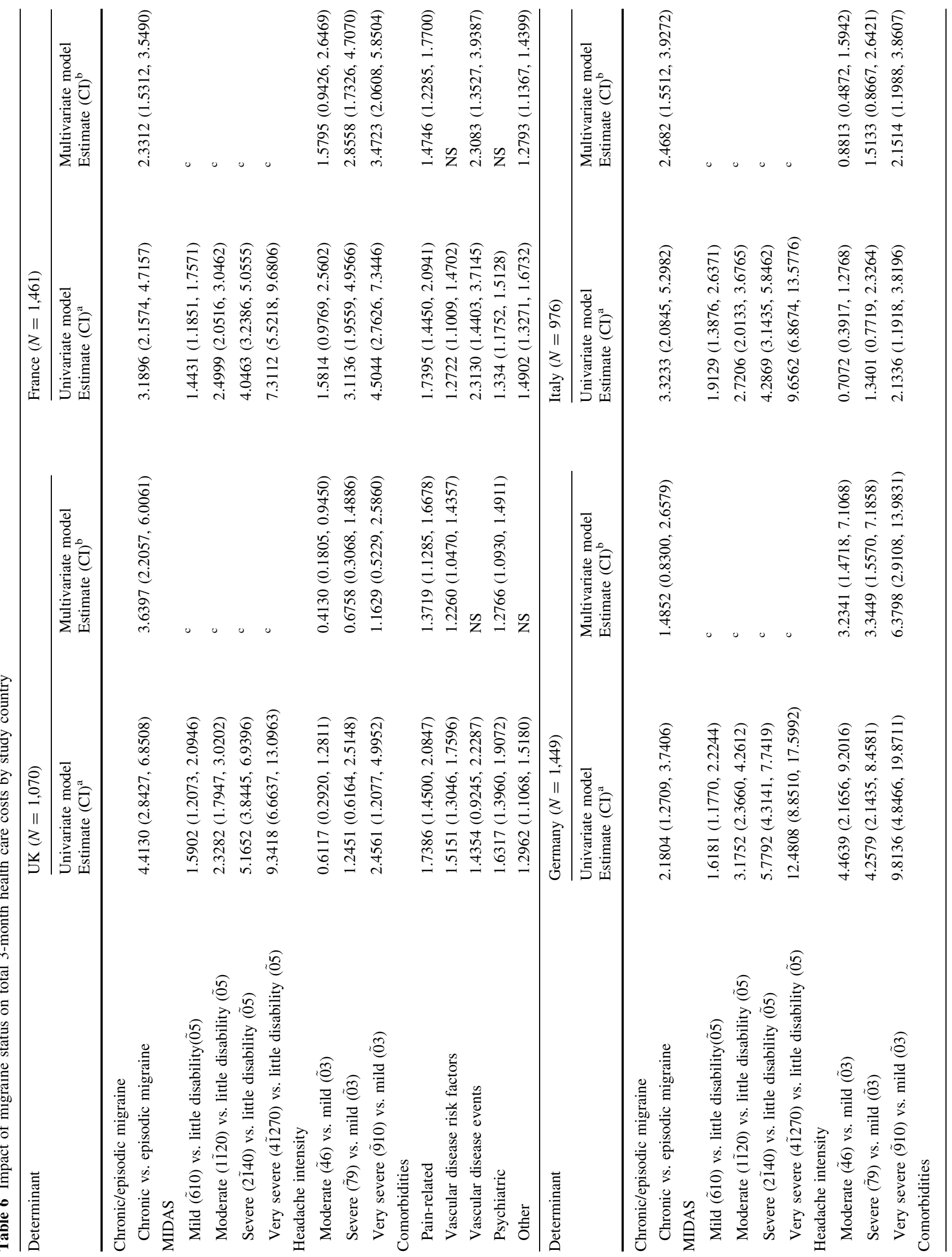




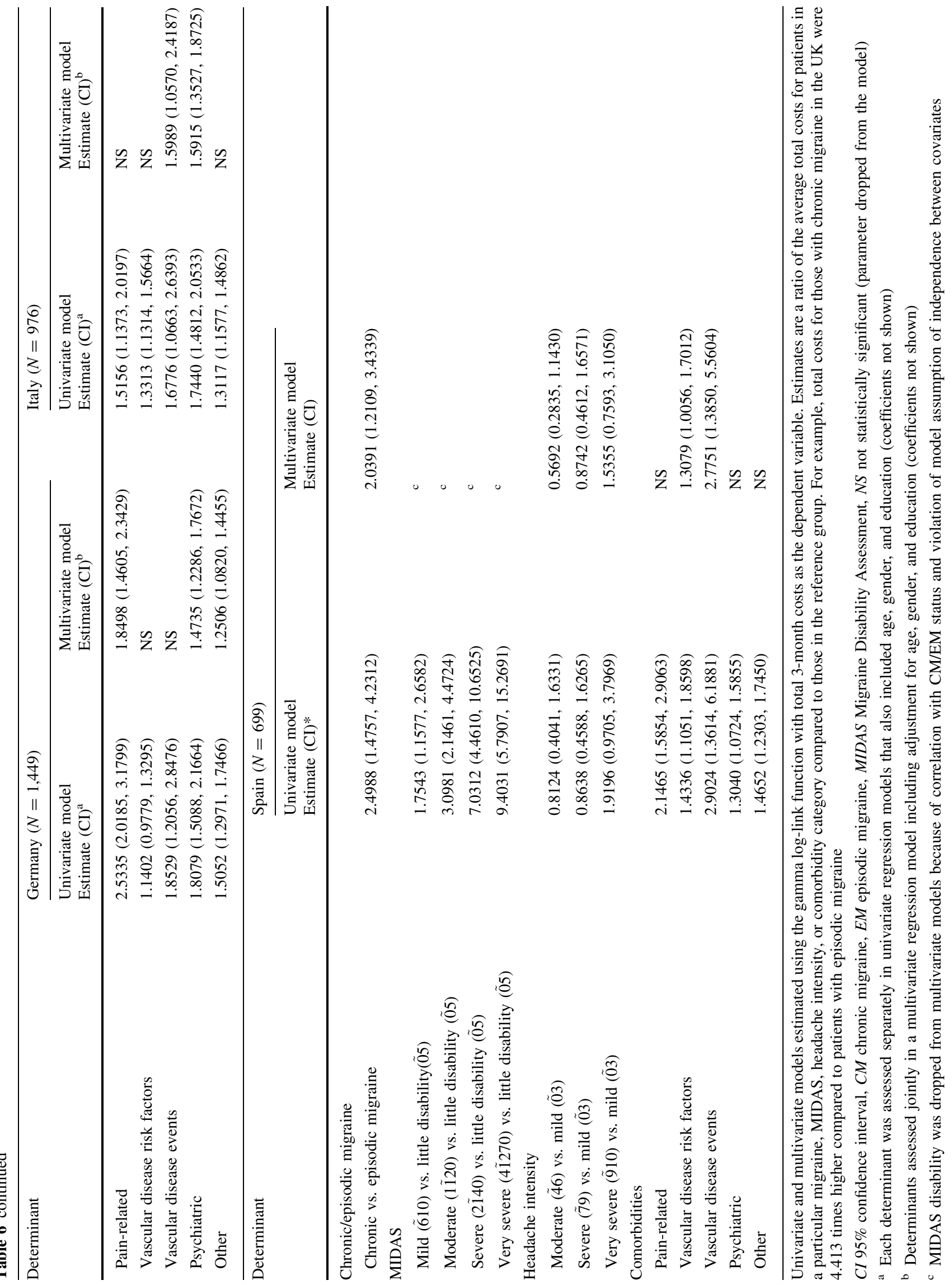


participants receiving treatment in the inpatient setting in the UK could be a reflection of better awareness and management of the condition rather than inappropriate care [53]. While a greater proportion of CM participants reported higher use of acute and preventive medications compared to EM in most countries, EM participants had higher rates of acute medication use in the UK and Germany and higher rates of preventive medication use in Italy and Germany. Whether the higher rate of medication use among EM represents a true phenomenon, or whether this finding is an artifact of the survey methodology with potential misclassification of EM and CM remains conjectural. However, it should be noted that less than onethird of CM participants in any country reported use of preventive medications, highlighting that many participants with $\mathrm{CM}$ are not receiving therapy which may be beneficial. While uncommon, the proportion of CM participants reporting occipital nerve block procedures were notably higher in the UK compared to other the countries. We feel this may reflect clinical practice, where physicians in the UK are more likely to be trained and actively performing this procedure, reinforcing the external validity of the survey results [54].

No previous studies have compared the cost of CM and EM in Europe. However, the difference in cost between CM and EM was generally similar to that observed in the US and Canadian subgroups of IBMS [18]. Prior studies quantifying the direct costs associated with migraine in general have reported lower estimates than ours, ranging from $€ 12$ in the UK to $€ 66$ in France, scaled to 2003 prices [55]. The 2004 annual direct cost of migraine was estimated at $€ 127.78$ per person in France [56]. In Spain, this was estimated at $€ 198.16$ at 2001 prices [57]. Differences in study methodology, and type of healthcare costs included make it difficult, if not impossible to directly compare the results of existing studies. However, older studies likely underestimate the current economic burden of migraine because of the introduction and widespread use of triptan medications for acute management since these studies were conducted. A more recent study on the cost of headache disorders in Europe estimated an annual per-person cost of $€ 1,177$ for migraine, with $93 \%$ of this cost attributed to indirect cost (e.g. work absenteeism) [58]. Considering only direct costs thus produces an annual per-person estimate considerably below ours.

This study is subject to a number of limitations and involved several assumptions. First, the majority of cost estimates were derived from publically available sources describing the costs of specific health care resources. Therefore, results are subject to variation in the unit cost estimates that are used as inputs into the economic analysis. Second, resource use data were collected as part of a voluntary online survey where an active e-mail account was a criterion for study. The extent to which restriction to those with internet access limits generalizability to the overall migraine population is unknown. Other limitations include possible selection bias toward more severe migraine participants due to the voluntary nature of the survey. The possibility of selecting a more severely impacted group of migraine participants may explain why our cost estimates are higher than those found in previous studies. The relatively high proportion of participants reporting use of opioids also suggests selection of a highly impacted sample of migraineurs. Healthcare resource use was collected via patient recall over the previous 3-month period (4 weeks for medication use). While recall bias is expected to be minimal for rare events such as emergency room visits and hospitalizations, the self-reported estimates may be less precise for common events such as use of acute medications and physician visits. The diagnostic component but not HRU section of the questionnaire was validated in English [59]. The entire questionnaire was translated and back-translated into other languages, but independent validation studies were not done in each language. Other limitations include the potential for bias in group comparisons due to unmeasurable differences between EM and CM participants, that our sample size for CM was notably smaller than that for EM, and that participants classified as $\mathrm{CM}$ were not assessed for meeting the ICHD-II criteria of $\geq 8$ migraine days per month, leaving the potential for misclassification of EM and CM.

CM is associated with greater headache-related disability and impairment of quality of life compared to EM [12-18]. The findings presented here demonstrate that in addition to social and quality of life burden, those with CM also incur greater economic burden. Prophylactic therapies to reduce headache-related disability or therapies that prevent the onset of CM could be important approaches for containing medical costs. The results of this study help to quantify the potential benefit of targeting this highly burdened group of individuals.

Acknowledgments This study was funded by Allergan, Inc. The authors wish to acknowledge Irina Proskorovsky, Karen Yeomans and Krista Payne (UBC) for contributions to design and execution of the IBMS and Imprint Publication Science for editorial support in the preparation and styling of this manuscript. Additionally, the authors would like to thank Zsolt Hepp (University of Washington) contributions to developing this manuscript.

Conflict of interest The study sponsor (Allergan, Inc.) was involved in the study design, data collection, data analysis, data interpretation, and the writing of the article. The sponsor and corresponding authors directed the research design and reviewed all major research decisions (i.e., study instruments, sampling, and analyses). The authors had full access to all data and had final responsibility for the decision to submit for publication.

Open Access This article is distributed under the terms of the Creative Commons Attribution License which permits any use, 
distribution, and reproduction in any medium, provided the original author(s) and the source are credited.

\section{References}

1. Stewart WF, Lipton RB, Whyte J, Dowson A, Kolodner K, Liberman JN, Sawyer J (1999) An international study to assess reliability of the Migraine Disability Assessment (MIDAS) score. Neurology 53:988-994

2. World Health Organization (2004) Headache disorders. http:// www.who.int/mediacentre/factsheets/fs277/en/. Accessed July 2010

3. Stovner LJ, Andree C (2010) Prevalence of headache in Europe: a review for the Eurolight project. J Headache Pain 11(4):289-299

4. Stovner LJ, Andree C, Eurolight Steering Committee (2008) Impact of headache in Europe: a review for the Eurolight project. J Headache Pain 9(3):139-146

5. Mennini FS, Gitto L, Martelletti P (2008) Improving care through health economics analyses: cost of illness and headache. J Headache Pain 9(4):199-206

6. Olesen J, Bousser MG, Diener HC, Dodick D, First M, Goadsby P, Gobel H, Lainez M, Lance J, Lipton R, Nappi G, Sakai F, Schoenen J, Silberstein SD, Steiner TJ (2006) New appendix criteria open for a broader concept of chronic migraine. Cephalalgia 26:742-746

7. Silberstein SD, Lipton RB, Sliwinski M (1996) Classification of daily and near-daily headaches: a field study of revised IHS criteria. Neurology 47:871-875

8. Bigal ME, Serrano D, Buse D, Scher A, Stewart WF, Lipton RB (2008) Acute migraine medications and evolution from episodic to chronic migraine: A longitudinal population-based study. Headache 48:1157-1168

9. Reed ML, Buse DC, Manack AN, Fanning KM, Serrano D, Turkel CC, Lipton RB (2011) Prevalence of chronic migraine (CM), headache-related disability and sociodemographic factors in the US population. Headache 51(S1):28

10. Natoli J, Manack A, Dean B, Butler Q, Turkel C, Stovner L, Lipton R (2010) Global prevalence of chronic migraine: a systematic review. Cephalalgia 30:599-609

11. Kavuk I, Cetindere U, Agelink MW, Diener HC (2003) Epidemiology of chronic daily headache. Eur J Med Res 8(6):236-240

12. Bigal ME, Rapoport AM, Lipton RB et al (2003) Assessment of migraine disability using the Migraine Disability Assessment (MIDAS) questionnaire. A comparison of chronic migraine with episodic migraine. Headache 3:336-342

13. Bigal ME, Serrano D, Reed M, Lipton RB (2008) Chronic migraine in the population: burden, diagnosis, and satisfaction with treatment. Neurology 71(8):559-566

14. Buse DC, Manack AN, Serrano D, Varon SF, Turkel CC, Lipton RB (2012) Headache-impact of chronic and episodic migraine: results from the AMPP study. Headache 52(1):3-17

15. Buse DC, Manack A, Serrano D, Turkel C, Lipton RB (2010) Sociodemographic and comorbidity profiles of chronic migraine and episodic migraine sufferers. J Neurol Neurosurg Psychiatry 81(4):428-432

16. Meletiche DM, Lofland JH, Young WB (2001) Quality of life differences between patients with episodic and transformed migraine. Headache 41:573-578

17. Stewart WF, Wood GC, Manack A, Varon SF, Buse DC, Lipton RB (2010) Employment and work impact of chronic migraine and episodic migraine. J Occup Environ Med 52(1):8-14

18. Stokes M, Becker WJ, Lipton RB, Sullivan SD, Wilcox TK, Wells L, Manack A, Proskorovsky I, Gladstone J, Buse DC, Varon SF, Goadsby PJ, Blumenfeld AM (2011) Cost of health care among patients with chronic and episodic migraine in Canada and the USA: results from the International Burden of Migraine Study (IBMS). Headache 51(7):1058-1077

19. Guitera V, Muñoz P, Castillo J, Pascual J (2002) Quality of life in chronic daily headache: a study in a general population. Neurology 58(7):1062-1065

20. Colás R, Muñoz P, Temprano R, Gómez C, Pascual J (2004) Chronic daily headache with analgesic overuse: epidemiology and impact on quality of life. Neurology 62(8):1338-1342

21. Antonaci F, Dumitrache C, De Cillis I, Allena M (2010) A review of current European treatment guidelines for migraine. J Headache Pain 11:13-19

22. Michel P, Auray J, Chicoye A, Dartigues J, Lamure M, Duru G, Henry P, Salamon R (1993) Prise en charge des migraineux en France: coût et recours aux soins. J d'Econ Méd 11:71-80

23. Neubauer G, Ujlaky R (2002) Migraine-a disease and its costs. Pharm Unserer Zeit 31:494-497

24. van Roijen L, Essink-Bot ML, Koopmanschap MA, Michel BC, Rutten FF (1995) Societal perspective on the burden of migraine in The Netherlands. Pharmacoeconomics 7:170-179

25. Berg J, Stovner LJ (2005) Cost of migraine and other headaches in Europe. Eur J Neurol 12(Suppl. 1):59-62

26. Payne KA, Varon SF, Kawata AK, Yeomans K, Wilcox TK, Manack A, Buse DC, Goadsby PJ, Lipton RB, Blumenfeld AM (2011) The International Burden of Migraine Study (IBMS): study design, methodology and baseline cohort characteristics. Cephalalgia 31:1116-1130

27. Stewart WF, Lipton RB, Dowson AJ, Sawyer J (2001) Development and testing of the Migraine Disability Assessment (MIDAS) Questionnaire to assess headache-related disability. Neurology 56(6 Suppl 1):S20-S28

28. Stewart WF, Lipton RB, Kolodner K (2003) Migraine disability assessment (MIDAS) score: relation to headache frequency, pain intensity, and headache symptoms. Headache 43(3):258-265

29. Stewart WF, Lipton RB, Kolodner K, Liberman J, Sawyer J (1999) Reliability of the migraine disability assessment score in a population-based sample of headache sufferers. Cephalalgia 19:107-114

30. Blumenfeld AM, Varon SF, Wilcox TK, Buse DC, Kawata AK, Manack A, Goadsby PJ, Lipton RB (2011) Disability, HRQoL and resource use among chronic and episodic migraineurs: results from the International Burden of Migraine Study (IBMS). Cephalalgia 31(3):301-315

31. AMELI (2010) L'Assurance maladie en ligne. http://www.ameli. fr. Accessed May 2010

32. Kassenarztliche Bundesvereinigung (2010) Einheitlicher Bewertungsmassstab (EBM). http://www.kbv.de/8144.html. Accessed March 2010

33. Department of Health (2010) Publications and Statistics NHS Reference Costs 2007-2008. http://www.dh.gov.uk/en/Publicationsan dstatistics/index.htm. Accessed May 2010

34. PSSRU (2011) Unit Costs of Health and Social Care 2007 http://www.pssru.ac.uk/uc/uc2007contents.htm\#contents. Accessed May 2011

35. Ministero della Salute (2008) Tariffa euro in vigore da prenotazioni, Lombardia (unpublished)

36. Diario Oficial de Galicia, núm 199 del 9 de octubre 2009, pg 15997

37. Boletín Oficial del País Vasco, núm. 69 del 14 de abril del 2009

38. Boletín Oficial de la Junta de Andalucía, núm. 210 del 27 de octubre de 2005, pg 46

39. Diari Oficial de la Comunitat Valenciana, núm 5922 de 29 de diciembre del 2008, pg 93310

40. Curepoint (2010) Acupuncture in Bristol. http://www.curepoint. co.uk/acupuncture-fees.shtml. Accessed May 2010

41. Energetique Traditionnelle Chinoise (2010) http://www.energetiq uechinoise.com/index.php?id=1\#acupuncture. Accessed May 2010 
42. Consumer Eroski (2010) La acupunctura. http://www.consumer.es/ web/es/salud/investigacion_medica/2004/06/14/104193.php. Accessed May 2010

43. EUMed.it (2010) Tariffa Unica Convenzionale per le Prestazioni di Assistenza Ospedaliera per Acuti 2006. http://www.eumed.it/ drg/TUC_2006.pdf. Accessed May 2010

44. InEK-Institut für das Entgeltsystem im Krankenhaus (2010) G-DRG-System 2010. http://www.g-drg.de/cms/index.php/ inek_site_de/G-DRG-System_2010. Accessed March 2010

45. Registro de Altas de los Hospitales Generales del Sistema Nacional de Salud. CMBD (2010) Norma Estatal 2007 Ministerio de Sanidad y Politica Social. http://www.msc.es/estadEstudios/ estadisticas/cmbd.htm. Accessed April 2010

46. Williams AE, Lloyd AC, Watson L, Rabe KF (2006) Cost of scheduled and unscheduled asthma management in seven European Union countries. Eur Respir Rev 15:1-9

47. British National Formulary v58 (2010) http://bnf.org/bnf. Accessed May 2010

48. Nomenclátor de Facturación (2010) Ministerio de Sanidad y Politica Social de España. http://www.msps.es/profesionales/ farmacia/frmNomenclator.jsp. Accessed April 2010

49. Rote list (2010) http://www.rote-liste.de. Accessed March 2010

50. Pneumonet (2010) Area Scientifica. Prontuario. http://www.pneum onet.it/scientifico/prontuario/. Accessed May 2010

51. Consulting Room (2010) Vistabel information and background. http://www.consultingroom.com/Treatment_FAQs/Product_ Display.asp?Product_ID=98\&Vistabel- ${ }^{\circledR}$. Accessed May 2010
52. Ophthalmologic Centre for Diagnosis and Treatment (2010) http://www.ophtalmo-centre.fr/eng/techniques/esthetics.htm. Accessed May 2010

53. Nagy AJ, Gandhi S, Bhola R, Goadsby PJ (2011) Intravenous dihydroergotamine (DHE) for inpatient management of refractory primary headaches. Neurology 77:1827-1832

54. Afridi SK, Shields KG, Bhola R, Goadsby PJ (2006) Greater occipital nerve injection in primary headache syndromes-prolonged effects from a single injection. Pain 122:126-129

55. Berg J (2004) Economic evidence in migraine and other headaches: a review. Eur J Health Econ 5(Suppl 1):S43-S54

56. Pradalier A, Auray JP, El Hasnaoui A, Alzahouri K, Dartigues JF, Duru G, Henry P, Lantéri-Minet M, Lucas C, Chazot G, Gaudin AF (2004) Economic impact of migraine and other episodic headaches in France: data from the GRIM2000 study. Pharmacoeconomics 22(15):985-999

57. Badia X, Magaz S, Gutiérrez L, Galván J (2004) The burden of migraine in Spain: beyond direct costs. Pharmacoeconomics 22(9):591-603

58. Linde M, Gustavsson A, Stovner LJ et al (2012) The cost of headache disorders in Europe: the Eurolight project. Eur J Neurol 19(5):703-711

59. Lipton RB, Stewart WF, Diamond S, Diamond ML, Reed M (2001) Prevalence and burden of migraine in the United States: data from the American Migraine Study II. Headache 41(7):646-657 